\title{
Synthesis and Properties of Superabsorbent Carboxymethyl Cellulose Graft- Poly(acrylic acid-co-acrylamide)
}

\author{
A. Hebeish, M.H. Elrafie, A. Rabie ", A.S. Aly and D. Refaat ${ }^{* *}$ \\ Textile Research Division, National Research Centre, \\ *Chemistry Department, Faculty of Science, Ain Shams \\ University and ${ }^{* *}$ Centre Metallgulical Research Institution, \\ Cairo, Egypt.
}

\begin{abstract}
A NEW cellulose-based superabsorbent polymer, carboxymethyl cellulose-graft-poly(acrylic acid-co-acrylamide), was prepared by the free-radical grafting solution polymerization of acrylic acid (AA) and acrylamide (AM) monomers onto carboxymethyl cellulose (CMC) in the presence of N,N'-methylenebisacrylamide (NMBA) as a crosslinker with a redox couple of sodium perborate, thiourea as an initiator. The influences of reaction variables such as crosslinker content, bath temperature, molar ratio of $\mathrm{AA}$ to $\mathrm{AM}$, and weight ratio of the monomers to $\mathrm{CMC}$ on the water absorbency of the carboxymethylcellulose- graft-poly(acrylic acidco-acrylamide) copolymer were investigated. The copolymer's structures were characterized with Fourier transform infrared spectroscopy (FTIR), Scanning Electron Microscope (SEM), Differential scanning calorimetry (DSC), Thermogravimetric Analysis (TGA).
\end{abstract}

Keywords: Copolymer, CMC superabsorbent, Crosslinking and Acrylic acid.

Carboxymethyl cellulose (CMC) is an important industrial polymer with a wide range of applications in drag reduction, detergents, textiles, paper, foods, drugs, and oil well drilling operation. CMC is a derivative of cellulose and formed by its reaction with sodium hydroxide and chloroacetic acid. It has a number of sodium carboxymethyl groups $\left(\mathrm{CH}_{2} \mathrm{COONa}\right)$, introduced into the cellulose molecule, which promote water solubility ${ }^{(1)}$. The various properties of CMC depend upon three factors: molecular weight of the polymer, average number of carboxyl content per anhydroglucose unit, and the distribution of carboxyl substituents along the polymer chains ${ }^{(2-4)}$. The most important properties of CMC are viscosity building and flocculation. Among all the polysaccharides, CMC is easily available and it is also very cheap. It has high shear stability. CMC is also used as a base for fabrication of superabsorbants.

Superabsorbents can be applied to many industrial applications, such as baby diapers, personal hygiene products, controlled drug release, horticulture, and agriculture $^{(5-8)}$. Other advanced applications include moisture sensors ${ }^{(9)}$, body water elimination systems for edemas occurring in many diseases, ${ }^{(10,11)}$ artificial muscles, and scaffolds for tissue engineering ${ }^{(12)}$.

\footnotetext{
${ }^{* *}$ Corrosponding author E- mail : dalia.refat@yahoo.com
} 
A superabsorbent is a new kind of functional polymer that has a weakly crosslinked three-dimensional network structure and the ability to absorb considerable amounts of water or other liquids (tens to thousands of times its own weight) in a relatively short time. Among the various superabsorbents, synthesized superabsorbent polymers from organic monomers have being paid particular attention because these materials possess good absorption capacity, desirable swelling rates, and receivable resistance to metallic ions and water retention ${ }^{(13-19)}$. However, in recent years, superabsorbent polymers prepared from natural polymers such as $\operatorname{starch}^{(20-22)}$, chitosan ${ }^{(23)}$, poly(amino acid)s ${ }^{(24)}$, and carrageenan ${ }^{(25,26)}$ have received increasing interest because they are environmentally friendly, biodegradable, and independent of oil resources and people are paying more and more attention to environmental preservation. Cellulose and its derivatives are also attracting a great deal of interest again for preparing superabsorbent polymers because of their biodegradable characteristics ${ }^{(27,28)}$, their natural abundance, and potentially high absorption properties ${ }^{(11,29,30)}$. Cellulose is one of the main constituents of natural plant fibers such as cotton, wood, and jute ${ }^{(31)}$. Its derivatives are among the main raw materials used for synthesizing early superabsorbent polymers ${ }^{(32-34)}$.

To synthesize successful superabsorbent polymers based on cellulose, the techniques mostly used are (1) the crosslinking graft copolymerization of hydrophilic vinyl monomers such as acrylic acid (AA) and acrylamide (AM) onto cellulose or its derivatives and (2) the crosslinking of cellulose derivatives with difunctional molecules such as divinyl sulfone as crosslinkers because they themselves possess nonideal water absorption, strong hydrogen bonds among cellulose molecules, high crystallinity, and poor water-soluble and forming properties. Many efforts have been made to synthesize cellulose-based superabsorbents and to improve the swelling capacity. For example ${ }^{(35)}$, synthesized highly water-absorbing AA-grafted carboxymethylcellulose (CMC) by photografting in the presence of $\mathrm{N}, \mathrm{N}$-methylenebisacrylamide (NMBA) as a crosslinker $^{(36)}$, reported partially hydrolyzed graft copolymers of crosslinked polyacrylamide on cellulose and its derivatives synthesized by a ceric salt initiation method $^{(37)}$, prepared AA-grafted and methacrylic acid grafted CMC superabsorbents by photoinitiation, ceric salt initiation, and radiation initiation, and the highest water absorbency obtained was less than $250 \mathrm{~g} / \mathrm{g} .^{(38)}$, prepared a superabsorbent cellulose-based hydrogel by crosslinking a sodium salt of CMC and hydroxyethyl cellulose with divinyl sulfone as a crosslinker.

This work is undertaken with a view to synthesize a newcellulose- based superabsorbent by simultaneously grafting two kinds of hydrophilic monomers, $\mathrm{AA}$ and $\mathrm{AM}$, onto CMC in the presence of the crosslinker NMBA, combining the high absorption capacity of poly(acrylic acid) and the strong resistance to metallic ions and fast swelling rate of polyacrylamide. The effects of various reaction parameters, such as the bath temperature, AA/AM molar ratio,monomer/CMC mass ratio, and crosslinker, on the water absorbency of the products, as well as their water retention and resistance to aqueous $\mathrm{NaCl}$ solutions, are investigated.

Egypt. J. Chem. 58, No.6 (2015) 


\section{Experimental}

Materials

Carboxymethyl cellulose (CMC) was prepared before in 2.2.4. in ChII, Acrylic acid (AA), acrylamide (AM), N,N'-methylenebisacrylamide (NMBA), Sodium perborate, thiourea, and other agents were all laboratory grade reagents.

\section{Method}

Synthesis of hydrogels

AA was first dissolved in distilled water to obtain an aqueous AA solution, and the solution was neutralized to $85 \%$ by the dropwise addition of a $5 \mathrm{~mol} / \mathrm{l}$ aqueous $\mathrm{NaOH}$ solution to form a mixture of AA and sodium acrylate. The whole process was performed in an ice- water bath to avoid possible polymerization of AA due to the increasing temperature caused by the neutralization reaction. An aqueous solution of CMC was placed in a $250-\mathrm{ml}$, four-necked flask equipped with a mechanical stirrer, a reflux condenser, a thermometer at room temperature to remove the dissolved oxygen from the solution. After a redox couple of sodium perborate and thiourea was added to the solution. it was gently stirred for 15 min to facilitate free-radical formation on the CMC backbone, AM and the partially neutralized AA were added to the flask. The crosslinker NMBA was added just after the addition of the monomers.

The reaction solution was heated in a water bath to desired temperatures to start the polymerization with constant stirring in an atmosphere of $\mathrm{N}_{2}$ for a certain time and then transferred to a stainless steel reactor for further reaction at $80^{\circ} \mathrm{C}$ for $2 \mathrm{hr}$. The obtained product was cut into small pieces and dried in vacuum at $70^{\circ} \mathrm{C}$ for $24 \mathrm{hr}$. The dry product was milled and sieved through a 40 mesh sieve. To remove soluble CMC, monomers, homopolymers, and other uncrosslinked copolymers from the products, these small pieces of copolymer were soaked in hot, distilled water, reaching equilibrium swelling under continuous stirring, then filtered. The process was repeated several times.

The product is refered to as carboxymethyl cellulose-graft poly( acrylic acidco-acrylamide) [CMC-g-poly(AA-co-AM)]. Unless otherwise stated, the basic composition was as follows: the molar ratio of AA to AM was $3: 1$; the total weight of the two monomers with respect to the CMC weight was $4: 1$; the weight percentages of the crosslinker and initiator with respect to the monomers were 0.70 and $1 \%$, respectively; the total weight percentage of AA, AM, and $\mathrm{CMC}$ with respect to distilled water was $11.6 \%$; and the volume of the reaction system was $100 \mathrm{ml}$.

\section{Characterization techniques \\ FTIR analysis}

The infrared spectra were registered from 48 scanning's at a resolution of $4 \mathrm{~cm}^{-1}$ by using JASCO FT/IR-6100 spectrophotometer (Japan). 
Scanning Electron Microscope (SEM)

SEM analysis was done using a scanning electron probe micro analyzer (JXA-840A, Japan). The specimen in the form of films were mounted on the specimen stabs and coated with thin film of gold by the sputtering method. The micrograph was taken at magnification of 1000 using (KV) accelerating voltage.

Differential scanning calorimetry (DSC)

Differential scanning calorimetry (DSC) has been one of the widely employed calorimetric methods to study the solid state of the drug in solid dispersions. DSC offers the possibility of detecting chemical interaction of DS and crosslinked carboxymethyl cellulose. DSC measurements were carried out on a modulated DSC Instrument : SDT Q600 V20.9 Build 20 equipped with a thermal analysis data system (TA instrument). Samples of 5-20 mg were placed in aluminium pans and sealed. The probes were heated from 25 to $400{ }^{\circ} \mathrm{C}$ at a rate of $10 \mathrm{~K} / \mathrm{min}$ under nitrogen atmosphere .

Thermogravimetric analysis (TGA)

Thermogravimetric analysis of samples $(4-5 \mathrm{mg}$ ) was carried out by using a NETZSCH thermal analyzer (TG209F1, NETZSCH-Geratebau GbH, Selb/ Bavaria, Germany) under nitrogen atmosphere at a heating rate of $10{ }^{\circ} \mathrm{C} / \mathrm{min}$ after the samples were kept in a vacuum oven at $60{ }^{\circ} \mathrm{C}$ for $48 \mathrm{hr}$. The range of scanning temperature was from 50 to $600{ }^{\circ} \mathrm{C}$.

\section{Study of properties}

Swelling ratio

Equilibrium swelling measurements for all the samples were carried out in distilled water using a Sartorius microbalance $\left(10^{-5}\right.$ sensitivity). The swelling ratio (SR) was measured by weighing samples before and after their immersion in distilled water for about $24 \mathrm{hr}$. The SR is defined as following:

$$
\mathrm{SR}=(\mathrm{Ws}-\mathrm{Wd}) / \mathrm{Wd}
$$

where Ws is the weight of the swollen hydrogel, and $\mathrm{Wd}$ is the weight of the dried sample (Wu et al. 2008).

Swelling in salt solution

Water absorbent capacity of superabsorbent hydrogel was determined in saline solution with different concentration of $\mathrm{NaCl}$ according to the above method.

\section{Results and Discussion}

\section{Spectral characterization}

FTIR-spectroscopy

In the FTIR spectrum (see Fig. 1a) of CMC a strong peak at $3443.8 \mathrm{~cm}^{-1}$ is observed due to $\mathrm{OH}$ stretching vibration. The band in the range of $1000-1166 \mathrm{~cm}^{-1}$ 
is assigned to the ether bonds. The absorption peak at $1635 \mathrm{~cm}^{-1}$ is related to the carboxylate. The peak at $2926.8 \mathrm{~cm}^{-1}$ is due to methylene.

As shown in Fig.1d. The band at $3462 \mathrm{~cm}^{-1}$ observed in the IR spectrum of the graft copolymer including [CMC-g-poly(AA-co-AM)] is attributed to the $\mathrm{NH}$ stretching of the AM unit, which overlaps the $-\mathrm{OH}$ stretching band of the $\mathrm{CMC}$ portion of the copolymer.

The peak at $2924 \mathrm{~cm}^{-1}$ is ascribed to the $\mathrm{C}^{-}-\mathrm{H}$ stretching of the polymer backbone. The peak at $1724 \mathrm{~cm}^{-1}$ is attributed to the carbonyl stretching of the carboxylic acid groups. The peak at $1670 \mathrm{~cm}^{-1}$ is assigned to the characteristic absorption bands of the carboxamide-functional groups of the amide moiety of the AM unit ${ }^{(23,39)}$. The very intense characteristic band at $1559 \mathrm{~cm}^{-1}$ is due to the $\mathrm{C}=\mathrm{O}$ asymmetric stretching in the carboxylate anion that is reconfirmed by another sharp peak at $1406 \mathrm{~cm}^{-1}$, which is related to the symmetric stretching mode of the carboxylate anion ${ }^{(40,41)}$. In addition, peaks at 1458 and $1179 \mathrm{~cm}^{-1}$ corresponding to the ${ }^{-} \mathrm{CO}^{-} \mathrm{O}^{-}$and $\mathrm{OH}$ coupling interactions of the carboxylic group and $\mathrm{C}^{-} \mathrm{N}$ stretching vibrations can also be observed ${ }^{(42)}$. The peak at 1055 $\mathrm{cm}^{-1}$, ascribed to the $\mathrm{C}^{-} \mathrm{O}-\mathrm{C}$ stretching interactions, can also be observed. A comparison of the two IR spectra shows that the characteristic absorption bands of AM and AA as shown in Fig.1 (b-c) repeating units appear in the spectrum of the copolymer, and this confirms the grafting copolymerization of AA and AM monomers onto the CMC backbone.

Characterization of the carboxymethyl cellulose hydrogel using SEM

Hydrogel water absorbency and its retention rate depend on hydrogel porosity and mean pore size. Hence, one of the most important properties which should be considered is hydrogel microstructure morphologies. This porous microstructure brings about an increased surface area and capillary effect. SEM micrographs of [CMC-g-poly(AA-co-AM)] superabsorbent hydrogel was observed and shown in Fig. 2. Obviously, the surface morphology of superabsorbent hydrogel has an undulant and coarse surface. This surface is convenient for the penetration of water into the polymeric network, and then may be of benefit to water absorbency of corresponding superabsorbent ${ }^{(43)}$.

Figure 2a surface morphology of CMC before grafting showing a granular structure, which has been changed to fibrillar form Fig. 2 (b-c) which shows the SEM images of the dried hydrogel samples before and after swelling in water. The surface of the samples exhibited macropores architecture. This suggested that the electrostatic repulsions caused by the ionic character of the carboxylate anions ( $\left.\mathrm{COO}^{-}\right)$in $\mathrm{CMC}^{-}$had enlarged the space in the networks of hydrogels.

The results revealed that the CMC contributed to the enhanced size of pore, the numerous water molecules could easily diffuse into hydrogels to form the large pores, leading to the higher swelling ratio. 

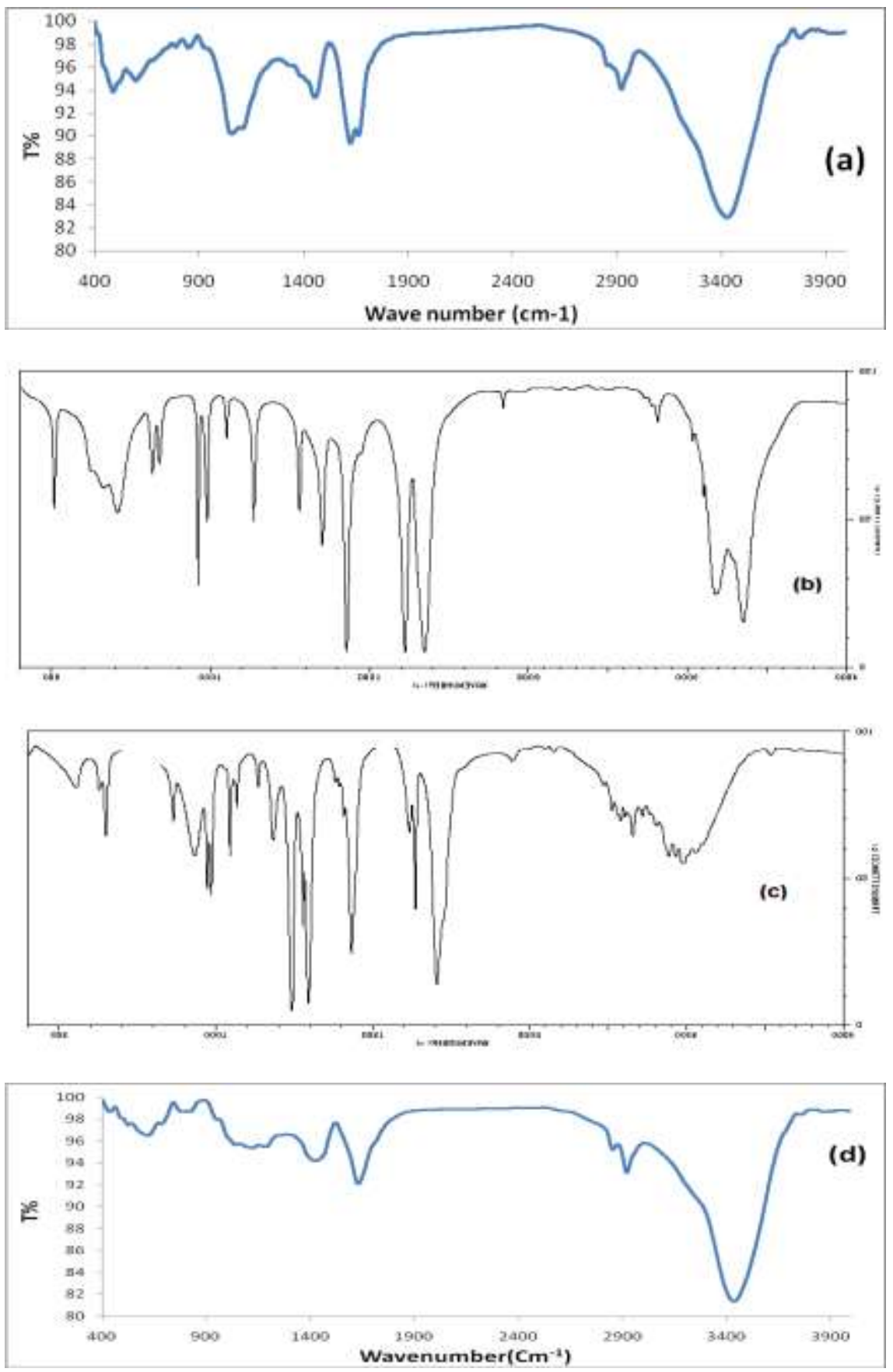

Fig.1. FTIR spectra of: (a) CMC; (b) acrylamide;(c) acrylic acid;(d) the resultant crosslinked graft copolymer.

Egypt. J. Chem. 58, No.6 (2015) 

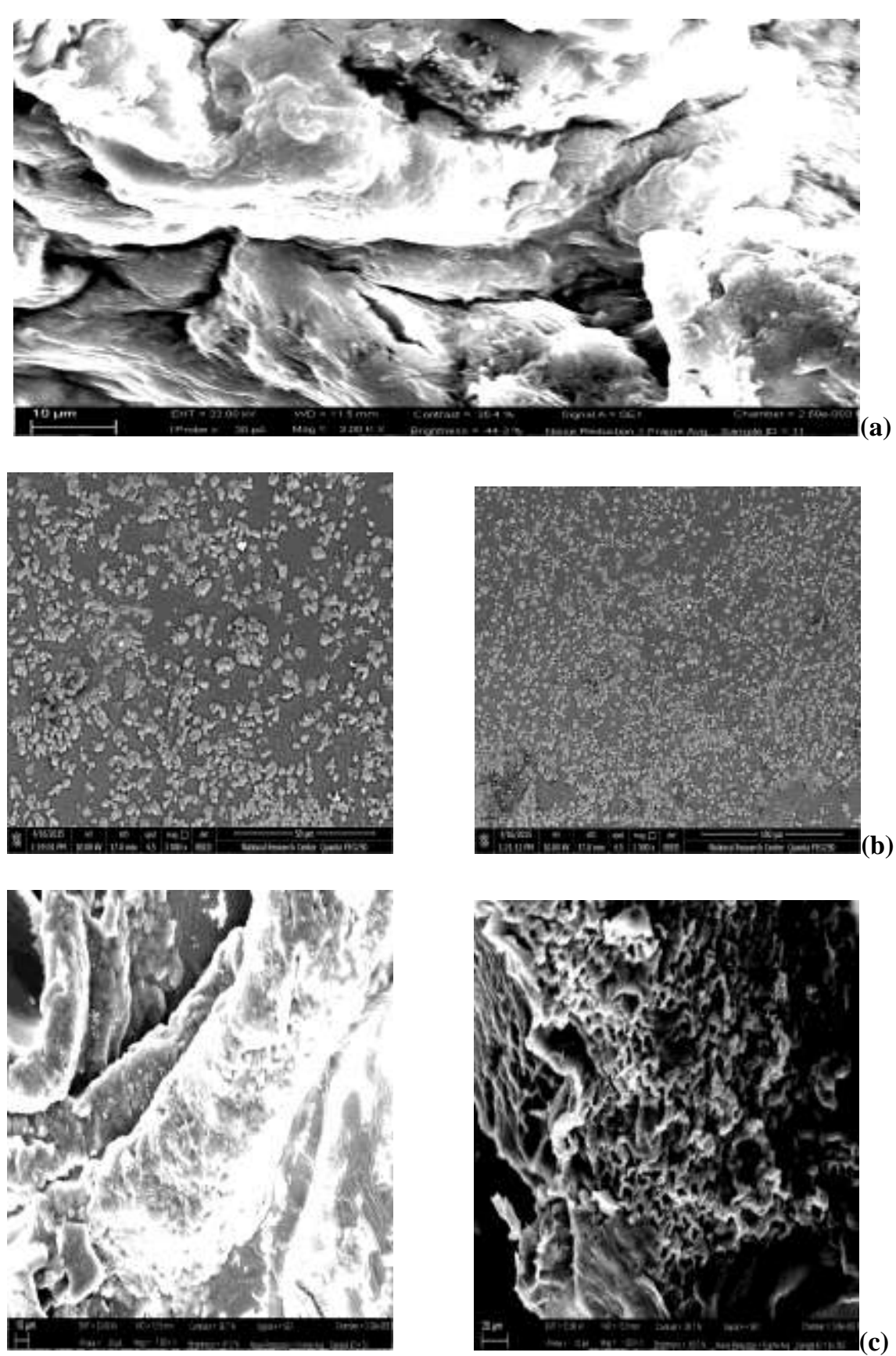

Fig.2. SEM of: (a) CMC; (b) the dry graft copolymer; (c) the graft copolymer after swelling.

Egypt. J. Chem. 58, No.6 (2015) 
Thermal gravimetric analysis

The TGA curves of CMC, is shown in Fig. 3a. In the case of CMC two distinct zones are observed where the weight is being lost. The initial weight loss is due to the presence of small amount of moisture in the sample. The second loss is due to the loss of $\mathrm{CO}_{2}$ from the polysaccharide. As there is a $\mathrm{COO}^{-}$group in the case of $\mathrm{CMC}$, it is decarboxylated in this temperature range. The rate of weight loss is increased with increase in temperature.

The DSC curves of CMC, is shown in Fig. 3b. CMC shows a distinct feature in the DSC curve having one endotherm $\left(76^{\circ} \mathrm{C}\right)$ and others at relatively higher temperatures due to the decomposition of the main chain. This step is followed by depolymerisation, which proceeds due to the cleavage of glycosidic linkages. The other small exothermic peaks at about $380{ }^{\circ} \mathrm{C}$ and above are due to the combustion of the degraded products.
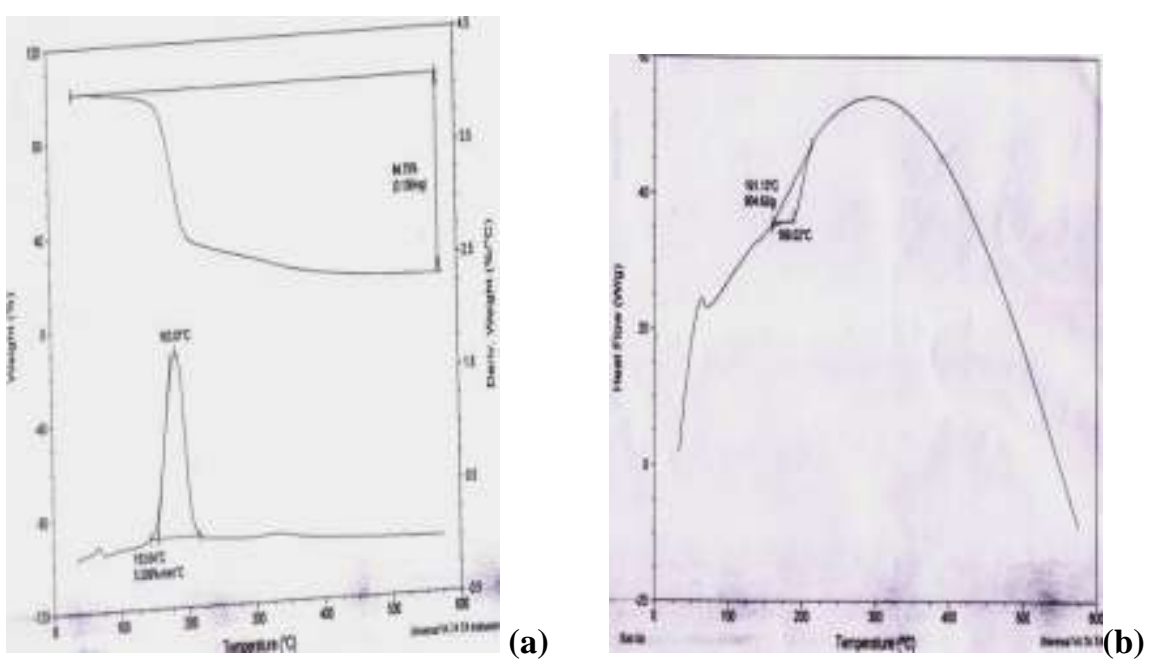

Fig. 3. (a) TGA ; (b) DSC for CMC.

Figure $4(\mathrm{a}, \mathrm{b})$ is the thermo gravimetric curve of superabsorbent hydrogel. The degradation of [CMC-g-poly(AA-co-AM)] superabsorbent hydrogel has four steps. At the initial stage, the minor weight loss of about $12.52 \mathrm{wt} \%$ from 150 to $240^{\circ} \mathrm{C}$ is ascribed to the dehydration of saccharide rings and the breaking of $\mathrm{C}-$ $\mathrm{O}-\mathrm{C}$ bonds in the chain of $\mathrm{CMC}^{(44)}$. The weight loss about $10.72 \mathrm{wt} \%$ within the temperature of $240-350 \circ \mathrm{C}$ might be due to elimination of $\mathrm{CO}_{2}$ molecule from the polymeric backbone ${ }^{(45)}$. Temperature at which maximum degradation occurs, i.e. $\mathrm{T}_{\max }$ has been found at $390 \circ \mathrm{C}$. The weight loss is about $50 \mathrm{wt} \%$. This $\mathrm{T}_{\max }$ can be attributed to the elimination of the water molecule from the two neighboring carboxylic groups of the polymer chains due to the formation of anhydride, mainchain scission and the destruction of crosslinked network structure ${ }^{(46)}$. The last stage is at $800 \circ \mathrm{C}$ where the weight loss is about $22.57 \mathrm{wt} \%$.

Egypt. J. Chem. 58, No.6 (2015) 

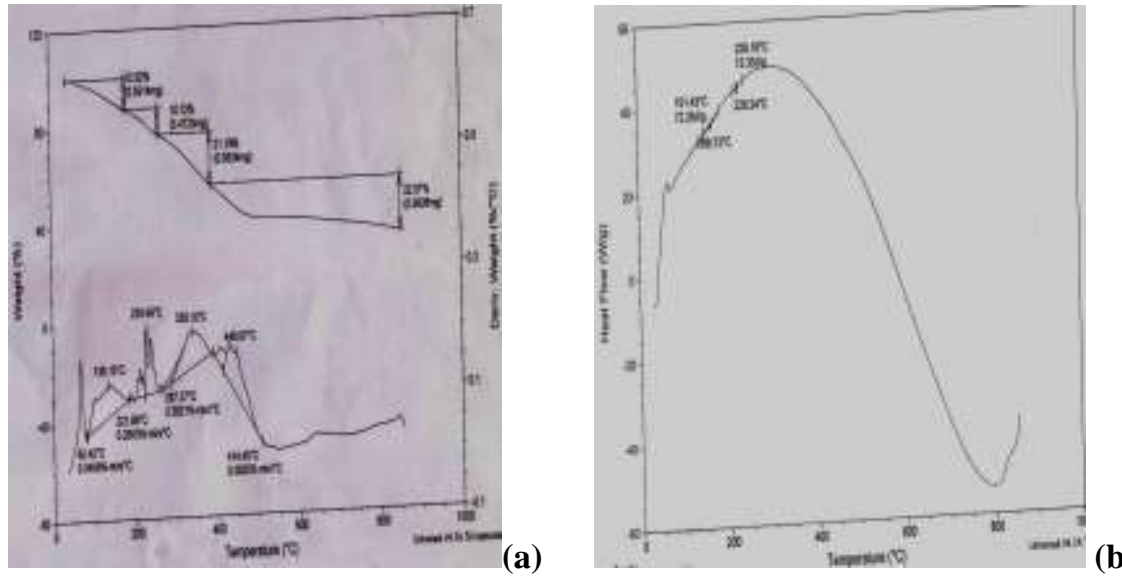

Fig. 4. (a)TGA ; (b) DSC for the graft copolymer .

Factor affecting the Swelling Ratio (SR)

Effect of the crosslinker content

Crosslinkers have to be present in a hydrogel to prevent the dissolution of hydrophilic polymer chains in an aqueous environment. The crosslinking density is an extremely important swelling-control element. The efficiency of crosslinker incorporation controls the overall crosslink density in the final hydrogel. In general, the crosslinking structure of a hydrogel decides both its dissolution and swelling capacity in an aqueous solution, so a moderate crosslinking degree is suitable for the absorbency enhancement of the resulting hydrogel. It is a wellknown rule for all hydrogels that a relatively small increase in the crosslinking degree can play a major role in modifying the properties of superabsorbent polymers. The influence of the crosslinker content on the swelling ratio of CMC$\mathrm{g}$ poly( AA-co-AM) is shown in Fig. 5 and Table 1.

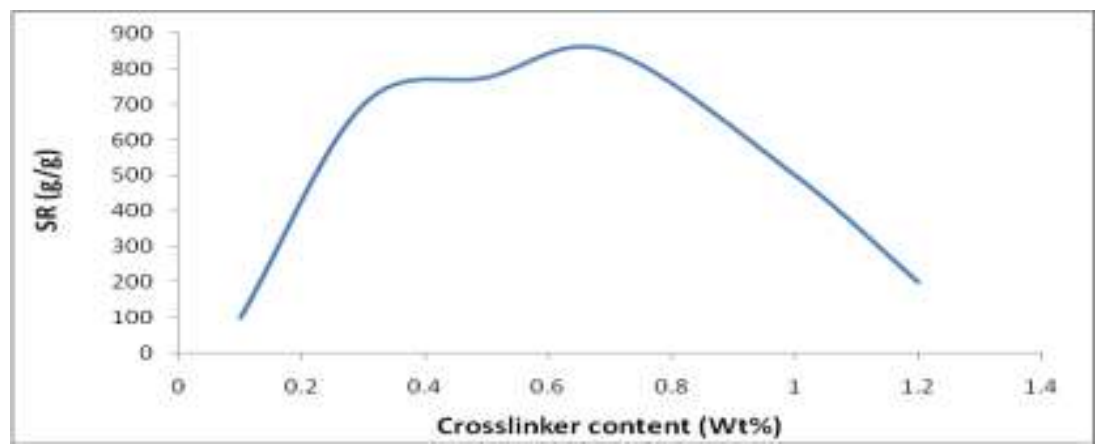

Fig.5. Effect of the crosslinker amount on the swelling ratio.

Egypt. J. Chem. 58, No.6 (2015) 
TABLE 1. Effect of the crosslinker amount on the swelling ratio.

\begin{tabular}{|c|c|c|}
\hline Sample No & $\begin{array}{c}\text { NMBA concentration } \\
(\mathbf{W t} \%)\end{array}$ & SR (g/g) \\
\hline 1 & 0.1 & 100.166 \\
\hline 2 & 0.3 & 700.403 \\
\hline 3 & 0.5 & 775.637 \\
\hline 4 & 0.7 & 850.251 \\
\hline 5 & 1 & 500.453 \\
\hline 6 & 1.2 & 200.20 \\
\hline
\end{tabular}

As the crosslinker content increases, the absorbency of the hydrogel for distilled water increases and reaches the maximum absorbency of $850.251 \mathrm{~g} / \mathrm{g}$ when the concentration of the crosslinker is $0.70 \mathrm{wt} \%$ of that of crosslinked copolymer, but the absorbency decreases as the concentration of the crosslinker is further increased.

The water absorbency increases as the crosslinker content increases up to $0.70 \mathrm{wt}$ $\%$ because of the formation of (1) a moderately crosslinked graft copolymer with a continuous network, (2) crosslinked, insoluble homopolymers, and (3) insoluble carboxymethyl cellulose- graft-N,N'-methylenebisacrylamide copolymer. In general, the decrease in the crosslinker content is limited by a value at which gel formation is prevented, causing a poorly crosslinked network dissolving in water during the swelling experiments. The as-prepared hydrogels do not possess good dimensional stability when the crosslinker concentration is lower than 0.1 wt $\%$ because the crosslinked network structure in the copolymer cannot form effectively, and AA, $\mathrm{AM}$, and $\mathrm{CMC}$ exist as monomers or linear low-molecular weight polymers. The absorbency of the resultant hydrogel cannot be measured despite high absorbency for the AA, AM, and CMC monomers. Under our experimental conditions, the crosslinker concentration should be higher than $0.1 \mathrm{wt} \%$.

The water absorbency decreases considerably with an increase in the crosslinker concentration from 0.70 to $1.2 \mathrm{wt} \%$. A higher crosslinker concentration will produce more crosslinked points in polymeric chains, cause a higher crosslinking density, and decrease the space between the copolymer chains, leading the pendant $\mathrm{AA}$ and $\mathrm{AM}$ chains on the CMC backbone to form a tight network. Consequently, the resulting highly crosslinked, rigid structure cannot be expanded and hold a large quantity of water. Nevertheless, crosslinking also increases the mechanical strength of these hydrogels.

Effect of the AA/AM molar ratio

The effects of various molar ratios of AA to AM on the swelling ratio of the products have been investigated, as shown in Fig. 6 \& Table 2. The swelling ratio increases with an increase in the molar ratio of AA to AM in the monomer feed.

Egypt. J. Chem. 58, No.6 (2015) 
The internal structural factors influencing the swelling characteristics of an absorbent polymer are the nature of the network charges, the crosslink density, the monomer composition, the gel modulus, and so forth. Because AM is a nonionic monomer, its dissociation degree in water is lower than that of ionic monomers such as AA and sodium acrylate. When a certain amount of AM together with AA is graft-copolymerized onto the CMC backbone, it not only weakens the hydrogen bond between water and carboxyl group, thereby reducing the water absorbency of the resultant hydrogel, but also exerts an influence on the water absorbency because of the synergistic effects of different hydrophilic groups. However, AM may enhance the salt resistance of the resultant hydrogel.

As the molar ratio of AA to AM increases, the number of osmotically active ionic carboxylate groups (from neutralized AA) in the CMC-g-poly(AA-co-AM) copolymer becomes much larger than that of nonionic carboxamide (from AM), which favors water absorbency because of the electrostatic repulsion from these carboxylate groups as main driving forces. As a result, the water absorption will increase.

TABLE 2. Effect of the AA/AM molar ratio on the swelling ratio.

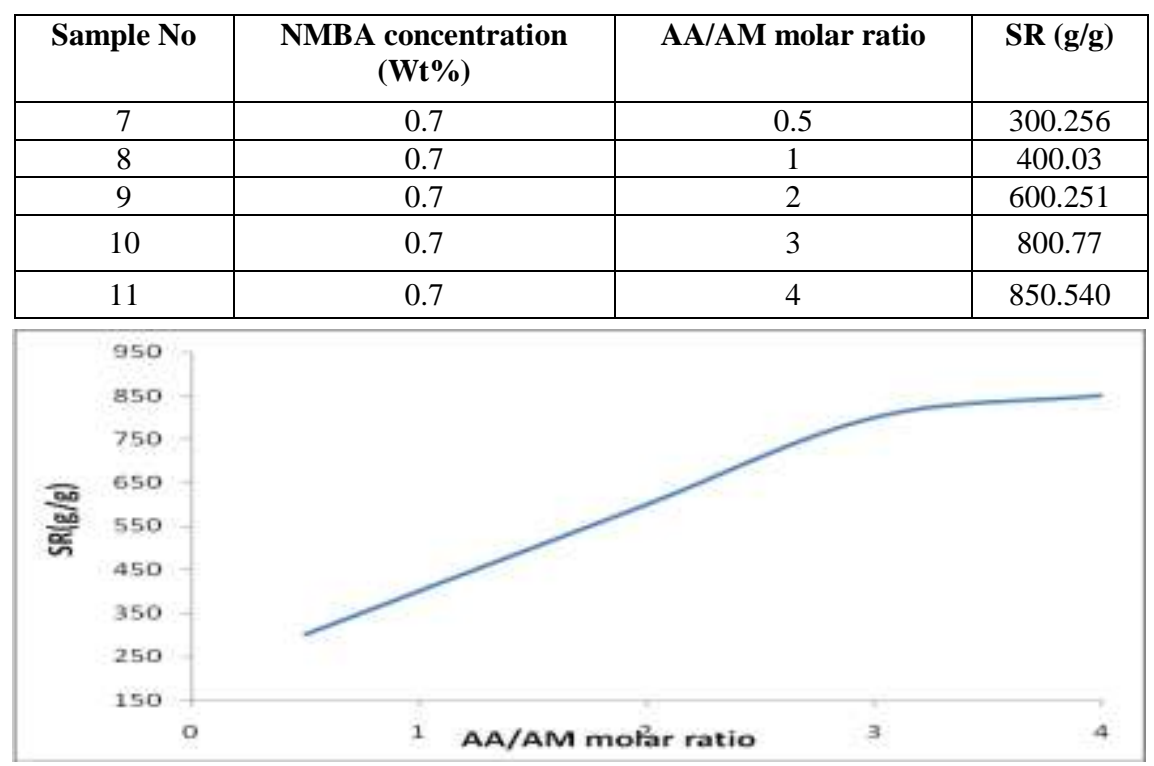

Fig. 6. Effect of the molar ratio of AA to AM on swelling ratio.

\section{Effect of the monomer/CMC weight ratio}

Figure $7 \&$ Table 3 shows the variation of the swelling ratio with the weight ratio of the monomers and CMC. The water absorbency rapidly increases almost linearly with an increasing monomer/CMC weight ratio. The reason is that the 
water absorbency of CMC is much lower than that of poly(acrylic acid-coacrylamide).

Actually, the copolymer contains four kinds of hydrophilic groups, namely, $-\mathrm{OH},-\mathrm{CONH}_{2},-\mathrm{COOH}$, and $-\mathrm{COONa}$. Among them, the $-\mathrm{COONa}$ group from partially neutralized $\mathrm{AA}$ will ionize into $\mathrm{Na}$ and $-\mathrm{COO}^{-}$ions in water and has much better absorbency capacity than the other three kinds of hydrophilic

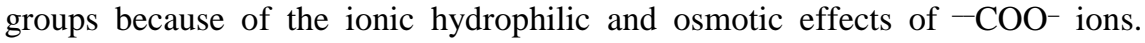
$\mathrm{CMC}$ has good hydrophilicity and can easily dissolve in water because of its linear macromolecular structure and $-\mathrm{OH}$ and $-\mathrm{CH}_{2} \mathrm{COOH}$ groups; this is not called swelling. Enhanced monomer content increases the diffusion rate of AA and AM molecules into the CMC backbone, and this improves the availability of monomer molecules in the vicinity of CMC macroradicals to produce a graft copolymer and subsequently improves its hydrophilicity and water absorbency.

TABLE 3. Effect of the monomer/CMC weight ratio on the swelling ratio.

\begin{tabular}{|c|c|c|c|c|}
\hline $\begin{array}{c}\text { Sample } \\
\text { No }\end{array}$ & $\begin{array}{c}\text { NMBA concentration } \\
(\mathbf{W t} \%)\end{array}$ & $\begin{array}{c}\text { AA/AM } \\
\text { molar ratio }\end{array}$ & $\begin{array}{c}\text { monomer/CMC } \\
\text { weight ratio }\end{array}$ & SR (g/g) \\
\hline 12 & 0.7 & 4 & 0.5 & 100.221 \\
\hline 13 & 0.7 & 4 & 1 & 400.03 \\
\hline 14 & 0.7 & 4 & 2 & 580.20 \\
\hline 15 & 0.7 & 4 & 3 & 800 \\
\hline 16 & 0.7 & 4 & 4 & 850.540 \\
\hline
\end{tabular}

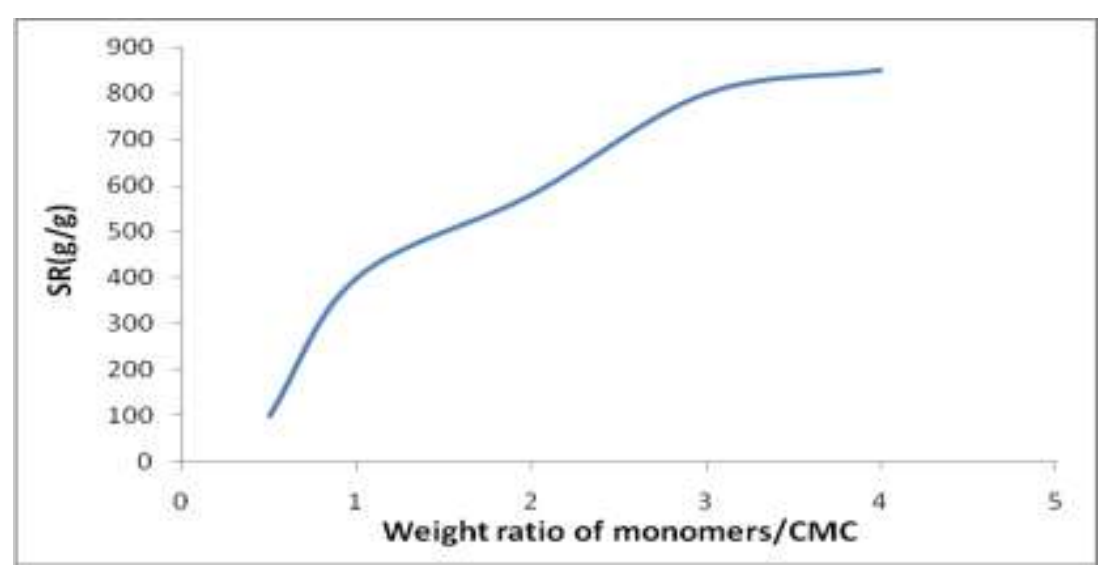

Fig.7. Effect of the monomer/CMC weight ratio on the swelling ratio.

\section{Effect of the bath temperature}

Figure $8 \&$ Table 4 demonstrates the effect of the bath temperature on the swelling ratio of the products. As the bath temperature increases, the swelling 
ratio increases, reaches a maximum value at $50^{\circ} \mathrm{C}$, and then decreases in swelling medium.

The increasing bath temperature before $50^{\circ} \mathrm{C}$ will result in a higher swelling rate, as-produced hydrogel.

TABLE 4. Effect of temperature on the swelling ratio.

\begin{tabular}{|c|c|c|}
\hline Sample No & Temperature $\left({ }^{\circ} \mathbf{C}\right)$ & SR (g/g) \\
\hline 17 & 30 & 150.003 \\
\hline 18 & 40 & 375 \\
\hline 19 & 50 & 850.540 \\
\hline 20 & 60 & 500 \\
\hline 21 & 70 & 200.35 \\
\hline
\end{tabular}

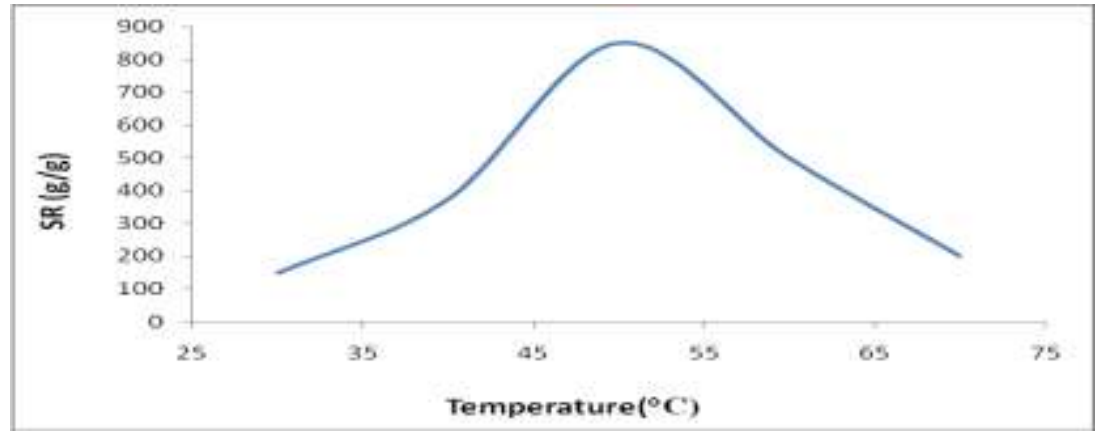

Fig. 8. Effect of bath temperature on the swelling ratio.

Effect of the concentration of $\mathrm{NaCl}$ aqueous solution on the swelling ratio

Table 5 shows the effect of the concentration of an aqueous $\mathrm{NaCl}$ solution on the water absorbency of the superabsorbents. The water absorbency decreases as the concentration of the aqueous $\mathrm{NaCl}$ solution increases. At the same time, the results of Table 5 also indicate that the resistance of CMC-g-poly (AA-co- AM) to metallic ions is ideal, and its absorbency is larger than $375 \mathrm{~g} / \mathrm{g}$ at a $0.3 \mathrm{wt} \%$ $\mathrm{NaCl}$ concentration.

It is known that the chemical potential of water in a superabsorbent is equal to that of the water surrounding the superabsorbent at the swelling equilibrium.

Because the ionic strength in the aqueous salt solution outside the superabsorbent is larger than that in distilled water, the osmotic pressure is greatly reduced. 
Therefore, the superabsorbent polymers cannot absorb an aqueous $\mathrm{NaCl}$ solution as much as distilled water.

TABLE 5. Effect of the concentration of the aqueous $\mathrm{NaCl}$ solution on the swelling ratio.

\begin{tabular}{|c|c|c|}
\hline Sample No & NaCl concentration $(\mathbf{W t} \%)$ & SR $(\mathbf{g} / \mathbf{g})$ \\
\hline 22 & 0.3 & 375 \\
\hline 23 & 0.6 & 234 \\
\hline 24 & 0.9 & 130 \\
\hline 25 & 1 & 100 \\
\hline 26 & 1.2 & 60 \\
\hline
\end{tabular}

\section{Conclusions}

A new cellulose-based superabsorbent polymer, CMC-g- poly(AA-co-AM), has been prepared by the graft polymerization of AA and AM onto CMC in an aqueous solution with NMBA as the crosslinker and sodium perborate/thiourea as a redox couple of the initiator. FTIR studies suggest that AA and AM monomers are graft-copolymerized onto CMC macromolecular chains. The crosslinker content, and bath temperature mainly affect the molecular weight and crosslinking density of the copolymer and the polymerization rate, respectively.

The TGA technique was employed to successfully characterize the weight loss and grafting information of superabsorbent. The surface morphology of superabsorbent hydrogel has an undulant and coarse surface.

It is a typical porous microstructure. The impact of salts on water absorbency of CMC-g- poly(AA-co-AM), superabsorbent hydrogel is relative to the concentration of salt solution. The swelling-loss behavior of the hydrogel occurred as the concentration of the external salt solution increased.

The crosslinked copolymer [CMC-g-poly(AA-co-AM)] has a collaborative effect on the swelling ratio of the products, and each of them presents an optimum value. The greater the weight percentage of the AA monomer in the starting stock is, the more numerous the ionic carboxylate groups are, and this greatly improves the swelling ratio. The maximum absorbency of the products obtained under the optimum reaction conditions is $850.540 \mathrm{~g} / \mathrm{g}$ for distilled water. In addition, the superabsorbent has good water retention and salt resistance.

\section{References}

1. Biswal, D.R. and Singh, R.P., Characterisation of carboxymethyl cellulose and polyacrylamide graft copolymer. Carbohydrate Polymers, 57, 379-387 (2004). 
2. Baar, A. and Kulicke, W.M., Nuclear magnetic resonance spectroscopic characterization of carboxymethyl cellulose. Macromolecular Cellular Physics, 195, 1483-1492 (1994).

3. Kamide, K., Okajima, K., Kowsaka, K., Matsui, T., Nomura, S. and Hikichi, K., Effect of the distribution of substitution of the sodium salt of carboxymethyl cellulose on its absorbency toward aqueous liquid. Polymer Journal, 17, 909-918 (1985).

4. Reuben, J. and Conner, H.T., Analysis of the carbon-13 NMR spectrum of hydrolyzed O-(carboxymethyl)cellulose : Monomer composition and substitution patterns. Carbohydrate Research, 115, 1-13 (1983).

5. Omidian, H., Rocca, J.G. and Park, K., Advances in superporous hydrogels. Journal of Controlled Release, 102 (1), 3-12 (2005).

6. Peppas, L.B. and Peppas, N.A., Dynamic and equilibrium swelling behaviour of pH-sensitive hydrogels containing 2-hydroxyethyl methacrylate. Biomaterials, 11 (9), 635-644 (1990).

7. Mucientes, A.E., Santiago, F. and Delgado, A.M., Effect of initial N,N'-methylene bisacrylamide concentration on the swelling behaviour of acrylic-based superabsorbent polymers. Pol. J. Chem. 79 (5), 897-905 (2005).

8. Bakass, M., Mokhlisse, A. and Lallemant, M., Absorption and desorption of liquid water by a superabsorbent polymer: Effect of polymer in the drying of the soil and the quality of certain plants. Journal of Applied Polymer Science, 83 (2), 234-243 (2002).

9. Gao, D.Y., Heimann, R.B., Lerchner, J., Seidel, J. and Wolf, G., Development of a novel moisture sensor based on superabsorbent poly(acrylamide)-montmorillonite composite hydrogels. Journal of Material Science, 36 (18), 4567-4571 (2001).

10. Sannino, A., Esposito, A., Rosa, A., Cozzolino, A., Ambrosio, L. and Nicolais, L., Biomedical application of a superabsorbent hydrogel for body water elimination in the treatment of edemas. J Biomed. Mater. Res., 67A, 1016-24 (2003)..

11. Esposito, A., Sannino, A., Cozzolino, A., Quintiliano, S.N., Lamberti, M., Ambrosio, L. and Nicolais, L., Response of intestinal cells and macrophages to an orally administered cellulose-PEG based polymer as a potential treatment for intractable edemas. Biomaterials, 26 (19), 4101-4110 (2005).

12. Nguyen, K.T. and West, J.L., Photopolymerizable hydrogels for tissue engineering applications. Biomaterials, 23 (22), 4307-4314 (2002).

13. Liu, Y., Xie, J.J., Zhu, M.F. and Zhang, X.Y., A study of the synthesis and properties of AM/AMPS copolymer as superabsorbent. Macromolecular Materials and Engineering, 289 (12), 1074-1078 (2004).

14. Omidian, H. and Zohuriaan-Mehr, M., DSC studies on synthesis of superabsorbent hydrogels. Journal of Polymer, 43 (2), 269-277 (2002). 
15. Rosa, F., Bordado, J. and Casquilho, M., Dynamic and equilibrium swelling of a sulfonic acid superabsorbent copolymer in salt solutions. Polymer Science Part B: Polymer Physics, 42 (3), 505-514 (2004).

16. Kang, H.M. and Xie, J.J., Effect of concentration and $\mathrm{pH}$ of solutions on the absorbency of polyacrylate superabsorbents. Journal of Applied Polymer Science, $\mathbf{8 8}$ (2), 494-499 (2003).

17. Rosa, F., Bordado, J. and Casquilho, M., Kinetics of water absorbency in AA/AMPS copolymers: applications of a diffusion-relaxation model. Polymer, $\mathbf{4 3}$ (1), 63-70 (2002).

18. Lee, W.F. and Yang, L.G., Superabsorbent polymeric materials. XII. Effect of montmorillonite on water absorbency for poly(sodium acrylate) and montmorillonite nanocomposite superabsorbents. Journal of Applied Polymer Science, 92 (5), 34223429 (2004).

19. Kabiri, K., Omidian, H., Hashemi, S.A. and Zohuriaan-Mehr, M., Synthesis of fast-swelling superabsorbent hydrogels: effect of crosslinker type and concentration on porosity and absorption rate. European Polymer Journal, 39 (7), 1341-1349 (2003).

20. Athawale, V.D. and Lele, V., Factors influencing absorbent properties of saponified starch-g-(acrylic acid-co-acrylamide). Journal of Applied Polymer Science , 77 (11), 2480-2485 (2000).

21. Zheng, T., Wang, P., Zhang, Z.Q. and Zhao, B.X., Microwave irradiation copolymerization of superabsorbents from cornstarch and sodium acrylate. Journal of Applied Polymer Science, 95 (2), 264-269 (2005).

22. Wu, J.H., Wei, Y.L., Lin, J.M. and Lin, S.B., Study on starch-graft-acrylamide/ mineral powder superabsorbent composite. Polymer, 44 (21), 6513-6520 (2003).

23. Mahdavinia, G.R., Pourjavadi, A., Hosseinzadeh, H. and Zohuriaan, M., Modified chitosan 4. Superabsorbent hydrogels from poly(acrylic acid-coacrylamide) grafted chitosan with salt- and $\mathrm{pH}$-responsiveness properties. European Polymer Journal, 40 (7), 1399-1407 (2004).

24. Kunioka, M., Biodegradable water absorbent synthesized from bacterial poly (amino acid)s. Macromolecular Bioscience, 4 (3), 324-329 (2004).

25. Francis, S., Kumar, M. and Varshneya, L., Radiation synthesis of superabsorbent poly(acrylic acid)-carrageenan hydrogels. Radiation Physics and Chemistry, 69 (6), 481-486 (2004).

26. Pourjavadi, A., Harzandi, A.M. and Hosseinzadeh, H., Modified carrageenan 3. Synthesis of a novel polysaccharide-based superabsorbent hydrogel via graft copolymerization of acrylic acid onto kappa-carrageenan in air. European Polymer Journal, 40 (7), 1363-1370 (2004). 
27. Lim, K.Y., Yoon, K.J. and Kim, B.C., Highly absorbable lyocell fiber spun from celluloses/hydrolyzed starch-g-PAN solution in NMMO monohydrate. European Polymer Journal, 39 (11), 2115-2120 (2003).

28. Sannino, A., Maffezzoli, A. and Nicalais, L., Introduction of molecular spacers between the crosslinks of a cellulose-based superabsorbent hydrogel: effects on the equilibrium sorption properties. Journal of Applied Polymer Science, 90 (1), 168$174(2003)$

29. Lionetto, F., Sannino, A. and Maffezzoli, A., Ultrasonic monitoring of the network formation in superabsorbent cellulose based hydrogels. Polymer, 46 (6),1796-1803 (2005).

30. Esposito, F., Del Nobile, M.A., Mensitieri, G. and Nicolais, L., Water sorption in cellulose-based hydrogels. Journal of Applied Polymer Science , 60 (13), 2403-2407 (1996).

31. Sahoo, P.K., Sahu, G.C., Rana, P.K. and Das, A.K., Preparation, characterization, and biodegradability of jute-based natural fiber composite superabsorbents. Advances in Polymer Technolog., 24 (3), 208-214 (2005).

32. Vitta, S.B., Stahel, E. P. and Stannet, V.T., The preparation and properties of acrylic and methacrylic acid grafted cellulose prepared by ceric ion initiation. II. Water retention properties. Journal of Applied Polymer Science, 32 (7), 5799-5810 (1986).

33. Yoshimura, T., Matsuo, K. and Fujioka, R., Synthesis and characterization of superabsorbent polymers from various kinds of cotton balls. Konbunshi Ronbunshu, 62 (7), 321-325 (2005)

34. Lepoutre, P., Hui, S.H. and Robertson, A.A., Water absorbency of hydrolyzed polyacrylonitrile-grafted cellulose fibers. Journal of Applied Polymer Science, 17 (10), 3143-3156 (1973).

35. Kuwabara, S. and Kubota, H., Water-absorbing characteristics of acrylic acidgrafted carboxymethyl cellulose synthesized by photografting. Journal of Applied Polymer Science, 60 (11), 1965-1970 (1996).

36. Yoshinobu, M., Morita, M. and Sakata, I., Porous structure and rheological properties of hydrogels of highly water absorptive cellulose graft copolymers. Journal of Applied Polymer Science, 45 (5), 805-812 (1992).

37. Kubota, H. and Kuwabara, S., Cellulosic absorbents for water synthesized by grafting of hydrophilic vinyl monomers on carboxymethyl cellulose. Journal of Applied Polymer Science, 64 (11), 2259-2263 (1997).

38. Lionetto, F., Sannino, A., Mensitieri, G. and Maffezzoli, A., Evaluation of the degree of cross-linking of cellulose-based superabsorbent hydrogels: A comparison between different techniques. Macromolecular Symposium, 200 (1), 199-207 (2003). 
39. Pourjavadi, A., Sadeghi, M. and Hosseinzadeh, H., Modified carrageenan. 5. Preparation, swelling behavior, salt- and $\mathrm{pH}$-sensitivity of partially hydrolyzed crosslinked carrageenan-graft-polymethacrylamide superabsorbent hydrogel. Advances in Polymer Technology, 15 (11), 645-653 (2004).

40. Pourjavadi, A., Mahdavinia, G.R. and Zohuriaan-Mehr, M.J., Modified chitosan. II. H-chitoPAN, a novel pH-responsive superabsorbent hydrogel. Journal of Applied Polymer Science, 90, 3115-3121 (2003).

41. Lu, S.J., Duan, M.L. and Lin, S.B., Synthesis of superabsorbent starch-graftpoly(potassium acrylate-co-acrylamide) and its properties. Journal of Applied Polymer Science, 88 (6), 1536-1542 (2003).

42. Ye, H., Zhao, J.Q. and Zhang, Y.H., Novel degradable superabsorbent materials of silicate/acrylic-based polymer hybrids. Journal of Applied Polymer Science , 91(2), 936-940 (2004).

43. Liang, R., Yuan, H.B., Xi, G.X. and Zhou, Q.X., Synthesis of wheat strawgpoly(acrylic acid) superabsorbent composites and release of urea from it. Carbohydrate Polymers, 77, 181-187 (2009).

44. Yang, F., Li, G., He, Y.G., Ren, F.X. and Wang, G.X., Synthesis, characterization, and applied properties of carboxymethyl cellulose and polyacrylamide graft copolymer. Carbohydrate Polymers, 78, 95-99 (2009).

45. Sand, A., Yadav, M. and Behari, K., Preparation and characterization of modified sodium carboxymethyl cellulose via free radical graft copolymerization of vinyl sulfonic acid in aqueous media. Carbohydrate Polymers, 81(1), 97-103 (2010).

46. Huang, Y.H., Lu, J. and Xiao, C.B., Thermal and mechanical properties of cationic guar gum/poly(acrylic acid) hydrogel membranes. Polymer Degradation and Stability, 92, 1072-1081 (2007). 


$$
\begin{aligned}
& \text { تحضير ودراسة خواص الكربوكسى مثيل سليلوز المطعم بولى الميلى } \\
& \text { حض الاكريليك المشارك الأكريلاميد }
\end{aligned}
$$

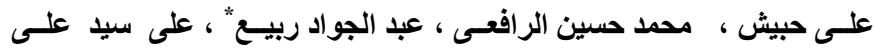

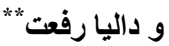

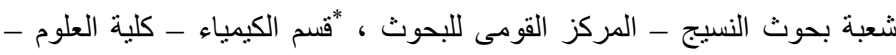

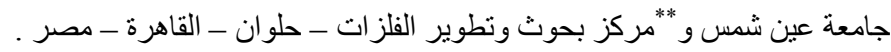

تحضير ودر اسة خو اص الكربوكسى ميثيل سليلوز المطعم بولى حمض الاكريليك

$$
\text { المشارك الأكريلاميد. }
$$

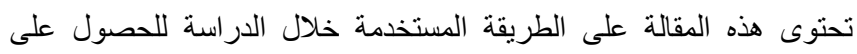

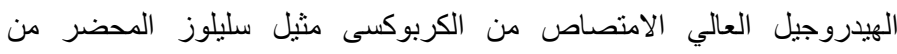

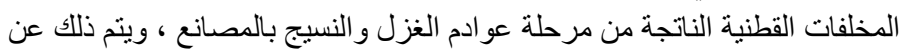

طريق:

• تحضير هيدروجيل من المادة السليلوزية المحضرة فى وجود الاكريليك أسيد

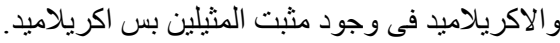

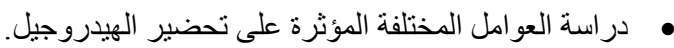

• توصيف الهيدروجيل المحضرة باستخدام التحاليل سبكتروسكوبية (الأشعة الهئ

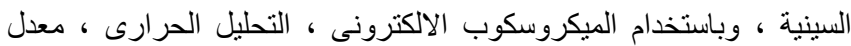

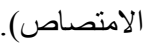

